\title{
Growth, population dynamics, and reproductive output model of the non-zooxanthellate temperate solitary coral Caryophyllia inornata (Scleractinia, Caryophylliidae)
}

\author{
Erik Caroselli, ${ }^{1}$ Francesco Ricci, ${ }^{1}$ Viviana Brambilla, ${ }^{1}$ Chiara Marchini, ${ }^{1}$ Giada Tortorelli, ${ }^{1}$ Valentina Airi, ${ }^{1}$ \\ Guido Mattioli, ${ }^{2}$ Oren Levy, ${ }^{3}$ Giuseppe Falini, ${ }^{4}$ Zvy Dubinsky, $^{3}$ Stefano Goffredo ${ }^{1 *}$ \\ ${ }^{1}$ Marine Science Group, Department of Biological, Geological and Environmental Sciences, University of Bologna, Bologna, \\ Italy \\ ${ }^{2}$ Operative Unit of Radiology and Diagnostics by Images, Hospital of Porretta Terme, Local Health Enterprise of Bologna, \\ Porretta Terme, Italy \\ ${ }^{3}$ The Mina and Everard Goodman Faculty of Life Sciences, Bar-Ilan University, Ramat-Gan, Israel \\ ${ }^{4}$ Department of Chemistry "Giacomo Ciamician", University of Bologna, Bologna, Italy
}

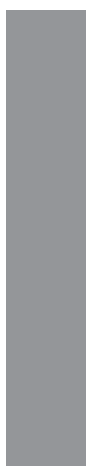

\begin{abstract}
Coral age can be strictly related to size, but processes like fragmentation, fusion, and partial colony mortality can decouple this relationship. When these phenomena are negligible, such as in solitary corals, agebased growth and population dynamics models can be used. In this study, the population size, structure, and growth rates of the temperate solitary coral Caryophyllia inornata were assessed at Elba Island (north-western Mediterranean Sea). Growth rate of this species decreased exponentially with age. The two growth curves estimated by field measurements and by growth band analysis provided homogeneous relationships between size and age. The decreasing number of individuals with age indicated a steady state population, with a turnover time of $4 \mathrm{yr}$ and a maximum life span of $22 \mathrm{yr}$. Maximum biomass yield and most reproductive output was by individuals of $8-15 \mathrm{yr}$ age classes. The life strategy was characterized by high fecundity, continuous embryo production, high larval output, and high larval mortality.
\end{abstract}

Investigations of scleractinian population dynamics began about 45 yr ago (Connell 1973). Since then, the knowledge has been extended through studies performed all around the world (e.g., Grigg 1977; Chadwick-Furman et al. 2000; Lins de Barros and Pires 2006; Nozawa et al. 2008; Caroselli et al. 2016a).

The demography of coral populations may reveal their health status and provide information to assess habitat stability and suitability (Grigg 1977; Meesters et al. 2001; Guzner et al. 2007; Caroselli et al. 2012b). Knowledge about population turnover and age of maximum biomass yield can be useful for reef restoration and conservation actions (Hughes 1984; Hughes and Connell 1987; Chadwick-Furman et al. 2000; Epstein et al. 2001; Goffredo and Lasker 2008; Vardi et al. 2012; Hernandez-Delgado et al. 2014). Demographic data obtained through growth and population dynamics models can benefit from reproductive data, which

*Correspondence: s.goffredo@unibo.it

Additional Supporting Information may be found in the online version of this article. are useful to assess the life strategy, reproductive success and colonization potential of corals (Santangelo et al. 2004; Goffredo et al. 2008, 2010). Furthermore, demographic traits may help to understand the complex relationships between organisms and their environment (Grigg 1984; ChadwickFurman et al. 2000; Meesters et al. 2001; Goffredo et al. 2010; Caroselli et al. 2012b). Scleractinian species are sensitive to environmental conditions (Lough and Barnes 2000; Goffredo et al. 2008; Rodolfo-Metalpa et al. 2008; Caroselli et al. 2015) such as temperature (Goffredo et al. 2007, 2008; Kružić et al. 2012), light (Rodolfo-Metalpa et al. 2008), water flow (Purser et al. 2010), nutrients (Muscatine et al. 1989; Orejas et al. 2011), waves (Lasker 1990), substrate slope and structure (Vertino et al. 2010), and pH (Goffredo et al. 2014; Fantazzini et al. 2015).

The skeletons of some gorgonians and many colonial and solitary scleractinians record one high density and one low density growth band each year, which can be used to determine their age (Dodge et al. 1974; Chadwick-Furman et al. 2000; Goffredo and Lasker 2008; Goffredo et al. 2008, 2010; Caroselli et al. 2012b, 2016a). The assessment of individual age is useful for analyses of linear growth rate (Dodge et al. 


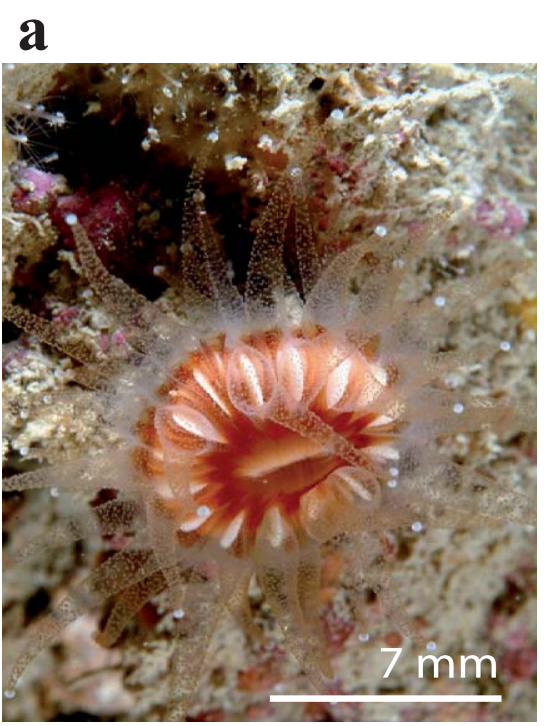

b

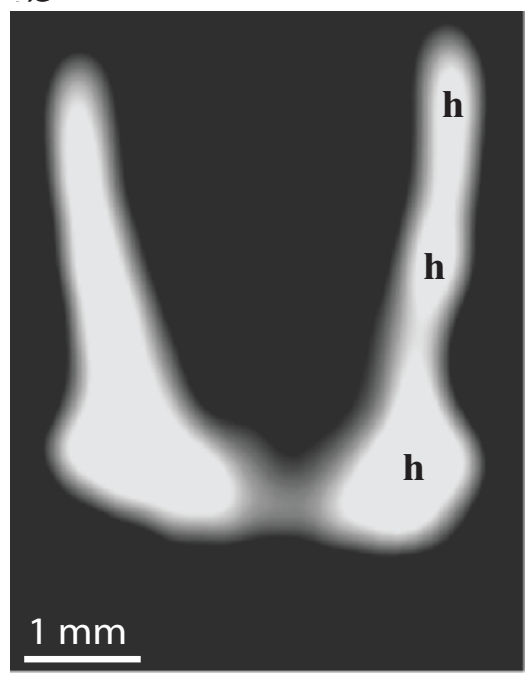

c

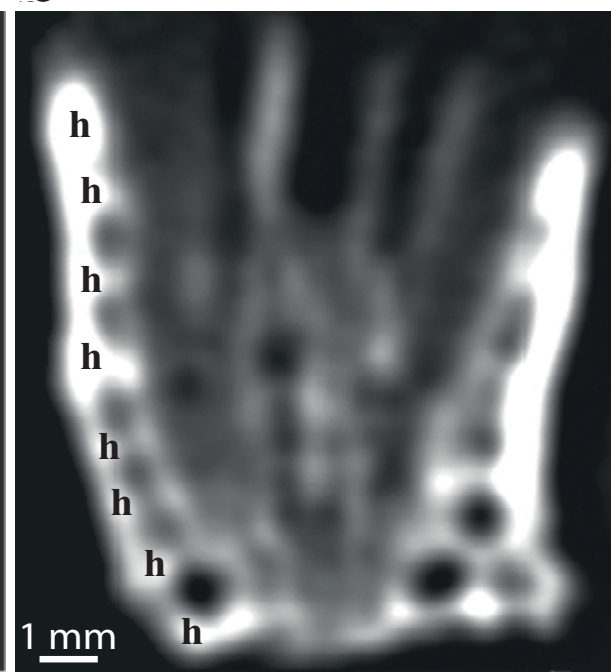

Fig. 1. Caryophyllia inornata. (a) Living specimen, (b) computerized tomography (CT) scan of a juvenile coral (3 yr); (c) CT scan of a mature coral (8 yr). h: high-density bands.

1974; Hudson 1981; Peirano et al. 1999), net calcification rate (Tanzil et al. 2009; Carricart-Ganivet et al. 2012; Caroselli et al. 2016b), and population dynamics (Grigg 1984; Chadwick-Furman et al. 2000; Goffredo et al. 2010; Caroselli et al. 2012b, 2016a). By integrating the above information with environmental data (Carricart-Ganivet 2004; Goffredo et al. 2008, 2009; Caroselli et al. 2012a, 2016a), it is possible to project future trends of coral populations in relation to environmental change (Cooper et al. 2008; Cantin et al. 2010; Caroselli et al. 2015, 2016b).

To apply some population dynamic models, an age-size relationship is needed (Beverton and Holt 1956; Madin et al. 2012). In certain forms of solitary and colonial corals this relationship can be determined by comparing their size and annual skeletal growth bands, which may be counted through computerized tomography (CT) scans (Grigg 1984; Chadwick-Furman et al. 2000; Goffredo et al. 2004, 2008, 2010; Goffredo and Lasker 2008; Lough 2008; Caroselli et al. $2012 b, 2016 a, b)$. Other solitary corals have external growth bands, which can be counted to estimate their age (Chadwick-Furman et al. 2000; Goffredo and Chadwick-Furman 2003). In species where processes that decouple individual age and size (i.e., fragmentation, fusion or partial colony mortality) do not occur, age-based growth and population dynamics models can be used (Hughes and Jackson 1985; Babcock 1991; Madin et al. 2012).

The present study focused on the non-zooxanthellate solitary scleractinian Caryophyllia inornata (Duncan, 1878), which lives in the Mediterranean Sea and North-Eastern Atlantic Ocean, from the United Kingdom to the Azores Islands, up to $100 \mathrm{~m}$ depth (Zibrowius 1980). C. inornata lives on shaded hard substrata such as walls and vaults of caves, crevices and sometimes the shaded portion of wrecks (Zibrowius 1980; Caroselli et al. 2015). The polyps of this species are gonochoric and brooding. Females, males, and sexually inactive polyps unusually and continuously produce apparently agamic embryos (Goffredo et al. 2012a; Marchini et al. 2015). The growth, net calcification rate, and demography of this species seem unaffected by temperature in the Mediterranean Sea, while populations are less stable and present deficits of young individuals with increasing solar radiation, possibly in relation to the associated decrease in plankton availability (Caroselli et al. 2015, 2016a,b).

This study aimed to: (1) assess if the growth bands of $C$. inornata are representative of field growth patterns; (2) assess the sexual reproductive output and larval mortality of this species at Elba Island; (3) compare the life history traits of this species with other co-located corals.

\section{Materials}

Field measurements

The studied population of C. inornata (Fig. 1a) was located at Elba Island (Italy, Tyrrhenian Sea, NW Mediterranean, $42^{\circ} 45^{\prime} \mathrm{N}, 10^{\circ} 24^{\prime} \mathrm{E}$ ). Twenty individuals of $\mathrm{C}$. inornata of different size (covering the whole range of observed coral size) were haphazardly selected and marked in situ by numbered plastic tags glued to the substratum (under the wings of a sunken plane wreck). Their growth rate was measured from December 2010 to November 2012. The length ( $L$ : maximum axis of oral disk) of each marked polyp was measured in situ with calipers $( \pm 0.5 \mathrm{~mm}$ ) every 8 months for $0.7-2 \mathrm{yr}$ (Table $1)$. Length was selected as the primary biometric parameter because it has the best fit to dry skeletal mass (Caroselli et al. 2015) and is used in all previous studies on this species 
Table 1. Number of Caryophyllia inornata polyps in each size class that were measured in the field for the indicated time interval.

\begin{tabular}{lcccc}
\hline & \multicolumn{3}{c}{$\begin{array}{c}\text { Duration of field } \\
\text { measurement (months) }\end{array}$} \\
\cline { 2 - 4 }$(\mathbf{m m})$ & $\mathbf{7 - 9}$ & $\mathbf{1 6 - 1 8}$ & $\mathbf{2 2 - 2 4}$ & Total \\
\hline $0-4$ & 1 & 1 & 1 & 3 \\
$4-8$ & 4 & 1 & 6 & 11 \\
$8-12$ & 1 & $/$ & 5 & 6 \\
Total & 6 & 2 & 12 & 20 \\
\hline
\end{tabular}

(Goffredo et al. 2012a; Caroselli et al. 2015, 2016a,b; Marchini et al. 2015). The period of measurements varied among individuals because some specimens died and were replaced (total loss $=10$ individuals of different size). Each dead specimen was replaced with the closest coral of similar size. For each coral, an average growth rate representing the growth during the entire observation period was estimated. Growth rates were normalized to $1 \mathrm{yr}$.

Temperature $\left({ }^{\circ} \mathrm{C}\right)$ at the sampling depth was recorded during the entire experimental period by three digital thermometers (i-Button, DS1921G-F5\#, Maxim Integrated Products, Dallas Semiconductors) placed at the experimental site, which recorded seawater temperature every $2 \mathrm{~h}$. Thermometers were replaced every 8 months to avoid problems of encrustation and overgrowth by marine organisms.

\section{Coral collection}

Samples were collected on $14^{\text {th }}$ May 2009 in the same site of field measurement. All samples present (241 specimens) in four haphazardly placed quadrats of $0.01 \mathrm{~m}^{2}$ each, arranged in a line crossing both wing tips of the plane wreck and at $\sim 3 \mathrm{~m}$ distance, were collected at $13 \mathrm{~m}$ depth, where high population abundance is reported (Caroselli et al. 2015) and where previous studies on the reproduction of $C$. inornata have been performed (Goffredo et al. 2012a; Marchini et al. 2015).

\section{Sample analysis}

Coral tissue was totally removed by immersing the samples in a $10 \%$ solution of commercial bleach for $3 \mathrm{~d}$ (Caroselli et al. 2011). Specimens were dried in an oven at $50^{\circ} \mathrm{C}$ for $4 \mathrm{~d}$ and observed under a stereoscope to remove fragments of substratum and calcareous deposits produced by other organisms. The low drying temperature was selected to avoid phase transitions in the skeletal aragonite/calcite composition (Vongsavat et al. 2006), which is under investigation using these samples in diffractometric analyses (Goffredo et al. 2012b). The biometric measurements of polyp length ( $L$ : maximum axis of the oral disc) were performed with a Vernier caliper (Metrica, Milano, Italy). The dry skeletal mass $(M)$ was measured with a digital precision balance.
A subset of 38 specimens of different size was randomly selected from the 241 collected corals, and each sample was dated by counting the growth bands on scans obtained by CT (Fig. 1b,c). This is based on the fact that some scleractinians (e.g., temperate corals) record in their skeletons one low-density band in summer and one high-density band in winter (Dodge et al. 1974; Goffredo et al. 2004, 2008, 2010; Peirano et al. 2005; Caroselli et al. 2012b, 2016a,b).

\section{Growth and population dynamics}

Growth rates were directly measured in the field, assessed by CT scan analysis and were fitted to the von Bertalanffy growth function (von Bertalanffy 1938):

$$
L_{t}=L_{\infty} \cdot\left(1-e^{-k t}\right)
$$

Where: $L_{t}=$ individual length at age $t ; L_{\infty}=$ asymptotic length (maximum expected length in the population); $k$ = growth constant (higher for a faster growth, smaller for a slower one); $t=$ individual age. The parameters $L_{\infty}$ and $k$ from field measurements were determined by applying the "Gulland and Holt plot" (Pauly 1984; Sparre et al. 1989; Goffredo et al. 2004, 2010). For the samples dated through CT scans, $L_{\infty}$ and $k$, including their confidence interval, were calculated by a least squares method using the software MATLAB R2012a (Caroselli et al. 2016a), whose fitting properties are higher (Sparre and Venema 1998) than traditional methods (e.g., Pauly 1984).

The obtained von Bertalanffy age-length function (Eq. 1) was used to estimate the age of collected samples for which CT scans were not performed, in order to reconstruct the population age structure. The regression analysis of population age-frequency distribution allows us to estimate the number of individuals at age zero $\left(N_{0}\right)$, the population structure stability $\left(R^{2}\right)$, and the instantaneous rate of mortality $(Z)$. The turnover time (i.e., mean life span) was obtained as $Z^{-1}$ (Pauly 1984; Goffredo and Chadwick-Furman 2003; Goffredo et al. 2004, 2010; Caroselli et al. 2012a). The survivorship curve, expressing the reduction in coral number over time, was calculated by the equation:

$$
N_{t}=N_{0} e^{-Z t}
$$

where $N_{t}$ is the number of individuals at age $t_{s}$ and $t$ is the individual age measured in years. Based on the survival curve, maximum life span was defined as the age at which $<0.5 \%$ of the population was still surviving (Sparre et al. 1989; Goffredo and Chadwick-Furman 2003; Goffredo et al. 2004, 2010; Caroselli et al. 2012a, 2016b).

The dry skeletal mass growth curve was estimated by applying to Eq. 1 the relationship between length and mass derived from a previous study on the biometry of $C$. inornata (Caroselli et al. 2015): 


$$
M=0.001 L^{2.915}
$$

The Beverton and Holt model (Beverton and Holt 1956) provides coral dry skeletal mass for each cohort yield (i.e., cohort yield $=$ dry skeletal mass $\times$ survivorship; see Grigg 1984; Chadwick-Furman et al. 2000; Goffredo and Chadwick-Furman 2003; Goffredo et al. 2004, 2010). Thus, the age at maximum biomass was determined to assess the threshold after which population biomass losses due to mortality prevail on biomass gains due to growth.

\section{Reproductive parameters}

The reproductive parameters were estimated only for females, assuming that each mature oocyte will result in a larva (planula), as in previous analyses on other Mediterranean species (Goffredo et al. 2010; Gizzi et al. 2014). Even though male and sexually inactive individuals of this species display an unusual embryo production (Goffredo et al. 2012a; Marchini et al. 2015), they were excluded by the analysis because the timing of their embryogenetic cycle is unknown.

Sex ratio, size at sexual maturity, average fecundity (number of planulae per unit polyp volume), and percentage of mature polyps in each age class were derived from previous studies (Marchini et al. 2015). The number of planulae of sexual origin released by each age class of females (biXi) was estimated by multiplying: fecundity (bi), number of individuals (Xi), female sex ratio (SR), and percentage of mature polyps (Fi).

\section{Statistical analysis}

To test the significance of growth rate differences among size classes, the non-parametric Kruskal-Wallis test was run (Kruskal and Wallis 1952) because data were not normally distributed. The test was computed using IBM SPSS Statistics 22.

\section{Results}

\section{Growth rate and lifetime growth curve}

Polyp growth rates measured in the field were plotted against polyp length according to the Gulland and Holt plot method (Fig. 2; Pauly 1984; Sparre et al. 1989). Growth rate decreased with age as a function of coral length (annual growth rate $=-0.156 \times L+1.654$ ). Field measurements indicated that on average, individuals of $0-4 \mathrm{~mm}$ in length grew

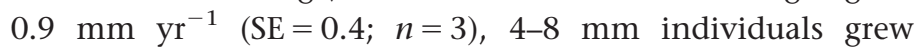
$0.7 \mathrm{~mm} \mathrm{yr}^{-1}(\mathrm{SE}=0.2 ; n=11)$ and $8-12 \mathrm{~mm}$ individuals dropped to $0.2 \mathrm{~mm} \mathrm{yr}^{-1}(\mathrm{SE}=0.1 ; n=6)$. Length explained $37.5 \%$ of growth rate variance (Fig. 2) and growth rates were significantly different among size classes (Kruskal Wallis test, $\mathrm{df}=2, p<0.05)$. Within size classes, individual growth rates were markedly variable (coefficient of variation $=0.7-1.8$ ). The population growth parameters estimated by field measurements were a growth constant $k=0.156(95 \% \mathrm{CI}=0.056-$ 0.256) and an asymptotic length $L_{\infty}=10.6 \mathrm{~mm} \quad(95 \%$

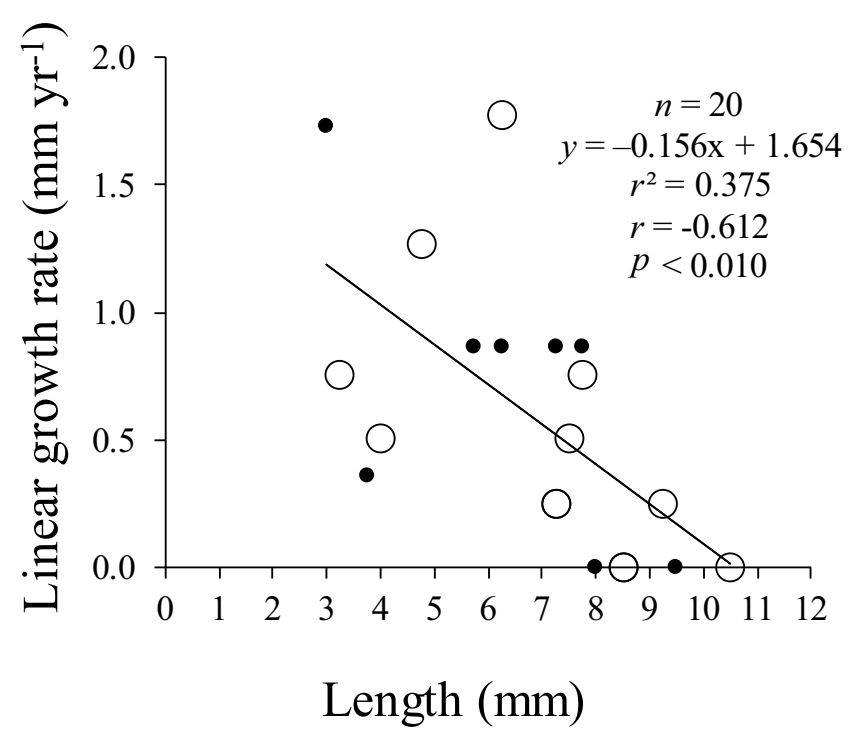

Fig. 2. Caryophyllia inornata. Variation in polyp linear growth rate from field measurements, corresponding to the Gulland and Holt plot used to estimate the parameters $K$ and $L_{\infty}$ of the von Bertalanffy growth function. Each data point represents a separate individual. White circles indicate the 12 corals that were measured for 2 full years (only 10 are visible because two pairs of points are overlapped). Black circles indicate the eight corals that were not measured for a full year or 2 full years. The indicated values and equation were calculated using the whole dataset of 20 samples.

$\mathrm{CI}=9.2-16.8)$. Using only the 12 corals that were measured for 22-24 months, remarkably similar growth parameters were obtained, which fell well within the CI of those derived using the whole dataset of 20 corals $(k=0.144$; $\left.L_{\infty}=10.7 \mathrm{~mm}\right)$.

The population growth parameters derived by CT scans were a growth constant $k=0.042 \quad(95 \% \mathrm{CI}=0.017-0.066)$ and an asymptotic length $L_{\infty}=22.5 \mathrm{~mm}(95 \% \mathrm{CI}=12.1-$ 32.9; Fig. 3). Thus, the von Bertalanffy growth functions obtained by field measurements and by CT scans provided similar predicted sizes per ages, since the confidence intervals of their $k$ and $L_{\infty}$ were overlapped. By applying Eq. 3 to the age-length growth curve by CT scans, a mass-length growth curve was obtained (Fig. 3), with an estimated asymptotic individual mass in the population of $M_{\infty}=8.7 \mathrm{~g}$.

\section{Population age structure and survivorship}

Converting from a size-frequency to an age-frequency distribution, the observed population mainly was dominated by young individuals (Fig. 4a). Sixty one percent of individuals belonged to age classes that had not reached sexual maturity, which was at $8 \mathrm{yr}$ and corresponded to $\sim 6.1 \mathrm{~mm}$ (Marchini et al. 2015). Despite the majority of individuals falling into immature age classes, population biomass was concentrated in sexually mature age classes (Fig. 4b). In fact, the percentage of biomass up to $8 \mathrm{yr}$ old was only $18 \%$, while observed biomass was maximum at $12 \mathrm{yr}$ (Fig. 4b). The 


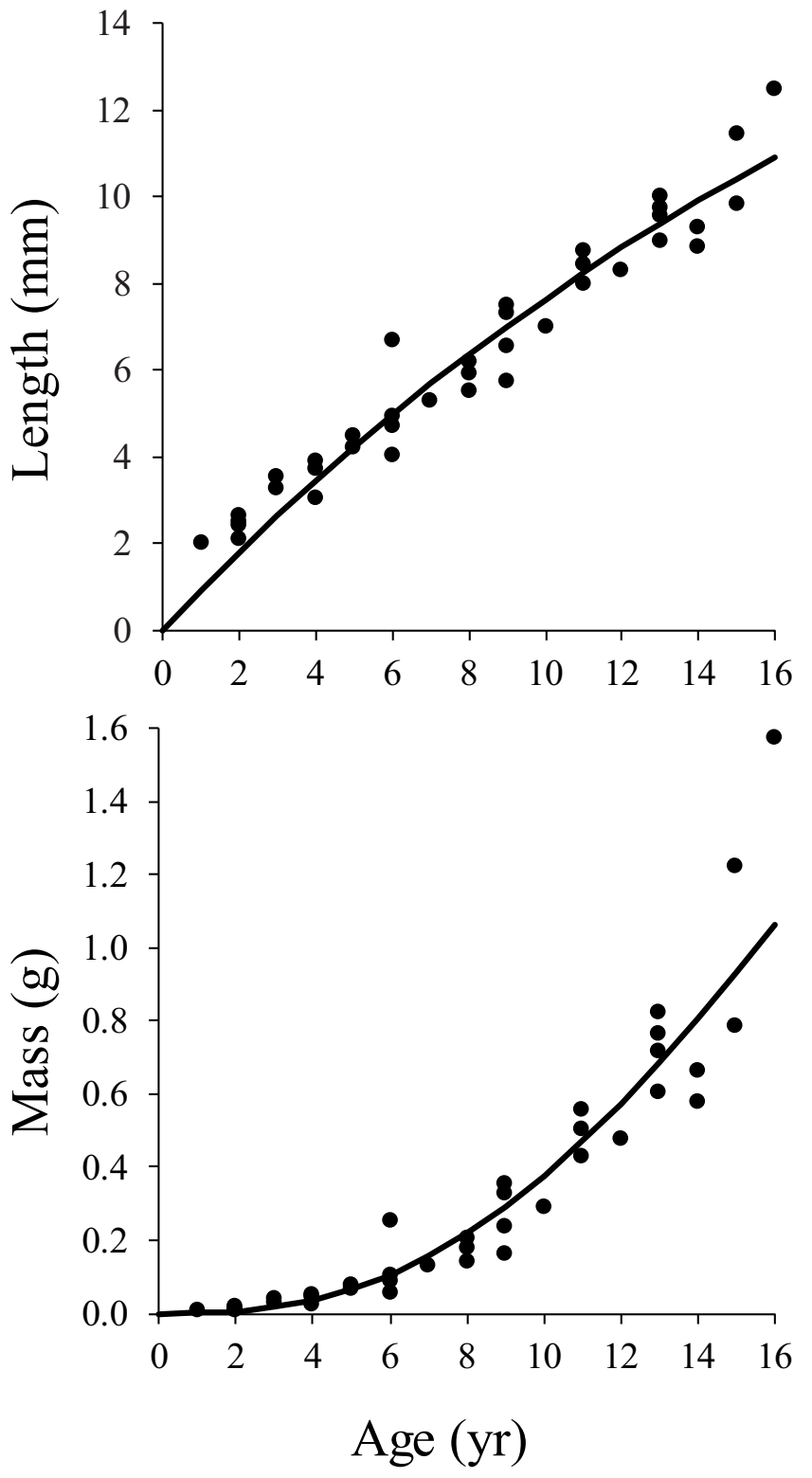

Fig. 3. Caryophyllia inornata. Age-length von Bertalanffy growth curve of individuals and age-specific growth curve of individual skeletal mass. Dots are length and mass data of individuals dated through CT scans.

largest observed individual was $12.5 \mathrm{~mm}$ in length and was estimated as $19 \mathrm{yr}$ old.

The observed age-frequency distribution allowed us to estimate population parameters and provided the instantaneous rate of mortality $\left(Z=0.241 \mathrm{yr}^{-1}\right)$ and population structure stability $\left(\mathrm{df}=11, R^{2}=0.777, p<0.001\right)$. Maximum life span was $22 \mathrm{yr}$, based on the estimated survival curve derived by Eq. 2 (Fig. 4c).

The age-specific growth and survival curves were used to estimate the theoretical biomass distribution of $C$. inornata individuals at Elba Island. The estimated biomass distribution was maximum at $10 \mathrm{yr}$ (Fig. 4b). At older ages, losses of biomass due to mortality overtook the gains due to individual growth.

\section{Life table}

Based on the population reconstructed through the Beverton and Holt model (Beverton and Holt 1956), female polyps released $9.58 \times 10^{6}$ larvae $\mathrm{m}^{-2}$ during $1 \mathrm{yr}$ (Supporting Information Table 1). Fifteen percent (95\% CI $=7-29 \%)$ of the population reached the age of sexual maturity. Most reproductive output (74\%) came from corals 8-15 yr old (Supporting Information Table 1). Older polyps (> $15 \mathrm{yr}$ ) represented only a small fraction (12\%) of the reproductive population, and thus contributed a smaller percentage (26\%) to reproductive output. Assuming local recruitment, larval mortality of sexually originated planulae released by female polyps was estimated as 99.97\% (95\% CI = 99.58-99.996\%; Supporting Information Table 1). The number of planulae needed for 1 recruit was $3188(95 \% \mathrm{CI}=239-23033)$, and for 1 reproductive polyp was 21921 (95\% CI = 3269-79593; Supporting Information Table 1).

\section{Discussion}

The study site at Elba Island is characterized by remarkable thermal differences among seasons. Mean seasonal temperature at the sampling depth spans $5.6^{\circ} \mathrm{C}$ (mean winter/ spring temperature $=14.3^{\circ} \mathrm{C}, 11.8^{\circ} \mathrm{C}$ to $18.7^{\circ} \mathrm{C}$; mean summer/fall temperature $19.9^{\circ} \mathrm{C}, 15.6^{\circ} \mathrm{C}$ to $22.8^{\circ} \mathrm{C}$ ). Therefore, for a reliable analysis, field measurements were performed throughout the year to include the whole range of differential seasonal growth rates. The measurement of annual growth rate is necessary to determine the applicability of von Bertalanffy growth model, which requires a negative exponential growth rate with increasing age (von Bertalanffy 1938; Pauly 1984; Sparre et al. 1989). Decreasing growth rate with age observed in the solitary coral C. inornata is similar to the growth pattern of other co-located solitary scleractinians in the Mediterranean Sea, such as Balanophyllia europaea (Goffredo et al. 2004, 2008) and Leptopsammia pruvoti (Goffredo et al. 2010; Caroselli et al. 2012b). Differential growth due to seasonal variations could be problematic when growth rate is normalized to $1 \mathrm{yr}$. However, only a few polyps were measured for less than $1 \mathrm{yr}$, thus this bias is limited in this study (Table 1). Moreover, the values of $k$ and $L_{\infty}$ obtained using the whole dataset were remarkably similar to those obtained using only the corals that were monitored for 22-24 months, thus indicating that the biases spread over different seasons and tend to balance each other. The wide variation in individual growth rate likely was due in part to the small sample size, which was only $n=3$ for the smallest size class $(0-4 \mathrm{~mm})$, and was not large for all size classes put together ( $n=20$; Fig. 2$)$. More accurate growth rates would be obtained if a study with a larger sample size were conducted. In $C$. inornata, the reliability of growth analysis 

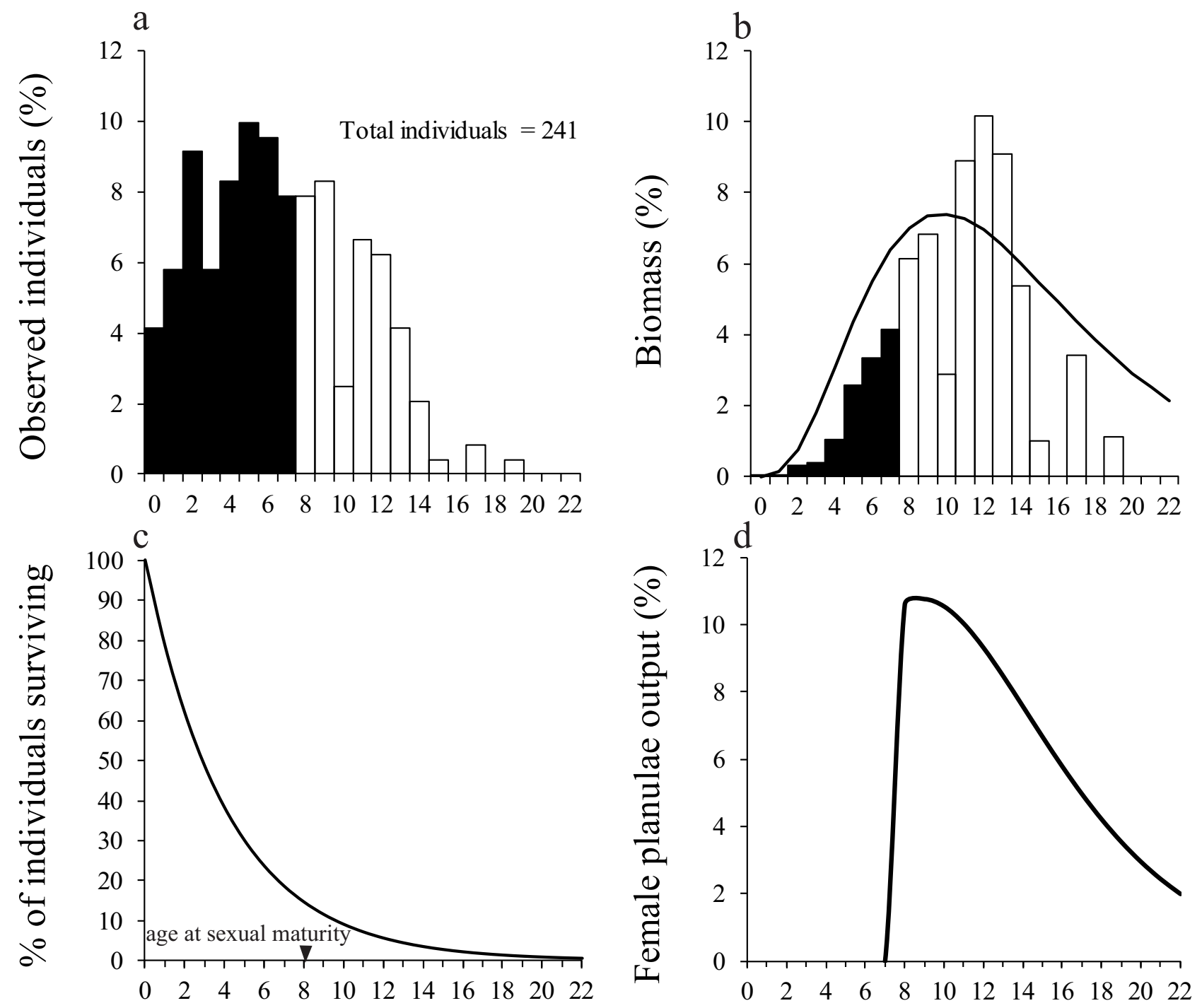

\section{Age (yr)}

Fig. 4. Caryophyllia inornata. (a) Age class distribution in terms of number of individuals. Total sampled area $=0.04 \mathrm{~m}^{2}$. (b) Observed dry mass (bars) and dry biomass curve (line). (c) Survivorship. (d) Female planulae output. Black bars indicate sexually immature age classes (Marchini et al. 2015).

through CT scans was confirmed by field measurements, because the two derived growth curves were highly similar and provided comparable predicted size and mass at a certain age. Also this result is in line with all other solitary Mediterranean corals for which field and CT growth curves were compared (Goffredo et al. 2004, 2010), confirming that CT scans are useful to assess coral growth without costly field measurements for a long time. The decreasing growth rate with age in $C$. inornata is an example of determinate growth (Sebens 1987), which is typical of some colonial octocorals (Goffredo and Lasker 2008), colonial scleractinians (Grigg and Maragos 1974; Johnson 1992; Sakai 1998), and solitary scleractinian corals (Gerrodette 1979; Yamashiro and Nishira 1998; Chadwick-Furman et al. 2000; Goffredo et al. 2008, 2010; Knittweis et al. 2009; Hamel et al. 2010; Caroselli et al. 2012b, 2016a,b). Determinate growth is a genetically controlled feature affected by environmental conditions (Sebens 1987), allowing the coral to allocate energetic resources to processes other than growth, such as reproduction. An unusual behavior occurs in the first years of sexual maturity ( $>8 \mathrm{yr}$ ) of this population: growth decreased but continued at a remarkable rate, until it dropped to a very low rate in polyps $>10 \mathrm{yr}$. Thus, even though sexually mature corals still invest energetic resources 
to increase their size, the reproduction effort is enough to sustain the population, whose $82 \%$ of biomass (39\% of individuals) is represented by sexually mature individuals.

A theoretical population in steady state (i.e., no age cohort missing or over-represented in response to disturbance events; Grigg 1984) age explains 100\% of the variance of age class frequency and the $R^{2}$ of the natural logarithm of the number of individuals against their corresponding age is equal to unity. Populations that deviate from steady state will have reduced $R^{2}$ values (Sparre et al. 1989; Goffredo et al. 2004; Caroselli et al. 2012b, 2016a). The stability value for the Elba population of $C$. inornata $\left(R^{2}=0.777\right)$ is within the range of other populations of solitary corals for which a steady state has been assumed, such as $B$. europaea $\left(R^{2}=0.935\right.$, Goffredo et al. 2004) and L. pruvoti $\left(R^{2}=0.839\right.$; Goffredo et al. 2010) in the NW Mediterranean and mushroom corals in the Red Sea $\left(R^{2}=0.725-0.986\right.$; Goffredo and Chadwick-Furman 2003). The Elba population is thus characterized by exceptionally high abundance (Caroselli et al. 2015) and high population structure stability. With increasing age, the age classes after $5 \mathrm{yr}$ (corresponding to $\sim 4 \mathrm{~mm}$ in length) showed an exponential decrease in their frequency (Fig. 4a). Age classes $<5$ yr were under-represented, which is typical for field sampling due to the difficulty in observing the smallest corals during diving (Grigg 1984; Babcock 1991; Goffredo and Chadwick-Furman 2003; Goffredo et al. 2008; Caroselli et al. 2012b, 2016a,b).

Past studies on the unusual reproductive biology of $C$. inornata (i.e., both sexual reproduction and continuous production of apparently agamic embryos in females, males, and sexually inactive individuals; Goffredo et al. 2012a; Marchini et al. 2015) enabled us to reconstruct a life table summarizing the principal demographic and reproductive parameters of this population. The estimated number of released planulae $\left(9.58 \times 10^{6} \mathrm{~m}^{-2} \mathrm{yr}^{-1}\right)$ was higher than for other co-located solitary corals (i.e., L. pruvoti and B. europaea at Calafuria, Italy; Goffredo et al. 2010; Gizzi et al. 2014). This result might depend on the life strategy of this species, characterized by high reproductive potential (Supporting Information Table 1; Marchini et al. 2015). Assuming local recruitment and given the ratio between larval output and recruit abundance, a larval mortality of $99.97 \%$ was estimated. This value is likely underestimated, because some recruits in the population may result from embryos asexually produced by male and sexually inactive polyps. Only 1 in 3188 released planulae successfully settled, and 21921 planulae were required to obtain 1 reproductive individual. Other Mediterranean coral species whose recruitment has been studied are the scleractinians L. pruvoti (Goffredo et al. 2010), B. europaea (Gizzi et al. 2014), and the octocoral Corallium rubrum (Santangelo et al. 2004), all with lower larval mortality compared to C. inornata $(97.7 \%, 98.6 \%$, and $94.6 \%$, respectively). The four species are co-located, colonize hard substrates, and share part of their depth distribution. However, while $B$. europaea is zooxanthellate and lives in open habitats, C. inornata, L. pruvoti, and $C$. rubrum dwell in the dark and are frequently found in the same coralligenous crevices and caves where their bathymetric distribution overlaps (10-60 m depth, Zibrowius 1980; Teixido et al. 2011).

Most reproductive output was by individuals of 8-15 yr (74\% planulae production; Fig. $4 \mathrm{~d}$ ), which belong to the age classes of maximum biomass (observed peak of biomass at $12 \mathrm{yr}$, estimated peak of biomass at $10 \mathrm{yr}$; Fig. 4b). This means that in the population, the same age classes were characterized by high reproductive output and maximum biomass production (Fig. 4b-d), while usually the energetic trade-off between growth and reproduction results in an age of maximum reproductive output that is older than the biomass peak. For instance, L. pruvoti reaches the biomass peak at $4 \mathrm{yr}$ and most reproductive output is by corals $4-8 \mathrm{yr}$ of age (Goffredo et al. 2010). Similarly, B. europaea reaches the biomass peak at $6 \mathrm{yr}$ and most reproductive output is at $7 \mathrm{yr}$ (Goffredo et al. 2004; Gizzi et al. 2014). Coincidence between age classes of maximum biomass and higher reproductive output might be due to the environmental conditions that characterize this site (i.e., absence of trophic competitors and artificial substratum), which could be optimal for C. inornata survival. The Elba Island population is the most abundant among those investigated (Caroselli et al. 2015). Moreover, southern populations show a lack of young individuals (possibly due to lower energetic resources from zooplankton, which is less abundant) while northern ones show lack of old individuals when compared with Elba (Caroselli et al. 2016b). The lack of old individuals in northern populations may be due to recent mass mortality events of benthic suspension feeders in the NW Mediterranean, caused by warming-enhanced stratification of seawater coupled with lower zooplankton availability in summer, which consequently decrease available energy for affected taxa (Coma et al. 2009).

It must be noted that the population sampled in this study was located on an artificial substratum and no other trophic competitors were present, resulting in an exceptional abundance relative to populations on natural substratum (Caroselli et al. 2015). Larval production and recruit number are expected to be lower on natural substrata, thus any comparison with other species requires caution. The planulae high mortality rate could be due to a reproductive strategy based on high production of inefficient larvae. To estimate the actual rate of self-recruitment (settlement at natal site), population genetics studies are needed and currently lacking. However, self-recruitment is likely, because the high larval mortality of $C$. inornata might be offset by planulae being heterotrophic and brooding (i.e., quickly settling; Jackson 1986; Harrison and Wallace 1990; Goffredo and Zaccanti 2004; Baird et al. 2009). 
This study extended the knowledge about $C$. inornata. The analysis of its ecological role and comparison with colocated species was possible by merging data about reproduction (Goffredo et al. 2012a; Marchini et al. 2015) with models of growth and population dynamics (von Bertalanffy 1938; Pauly 1984; Sparre et al. 1989). In summary, results indicate that: (1) skeletal growth bands of $C$. inornata reflect field growth patterns; (2) sexual reproductive output was $9.58 \times 10^{6}$ planulae $\mathrm{m}^{-2} \mathrm{yr}^{-1}$ with an estimated larval mortality of $99.97 \%$; (3) the obtained value of larval mortality is higher than in other co-located scleractinians and octocorals for which similar analyses were performed. The investigated site at Elba Island seems characterized by optimal environmental condition for this species, as suggested by remarkable abundance and high planulae output. High reproductive potential may be a characteristic of $C$. inornata that provides an advantage during interspecific spatial competition. Further analysis of the embryogenesis, larval features, and genetic structure of populations of this species could clarify the dispersal potential and rate of self-recruitment.

\section{References}

Babcock, R. C. 1991. Comparative demography of three species of scleractinian corals using age- and size-dependent classifications. Ecol. Monogr. 6: 225-244. doi:10.2307/ 2937107

Baird, A. H., J. R. Guest, and B. L. Willis. 2009. Systematic and biogeographical patterns in the reproductive biology of scleractinian corals. Annu. Rev. Ecol. Evol. Syst. 40: 551-571. doi:10.1146/annurev.ecolsys.110308.120220

Beverton, R. J. H., and S. V. Holt. 1956. A review of methods for estimating mortality rates in fish populations, with special reference to sources of bias in catch sampling. Rapp. P.-V. Reun. Cons. Int. Explor. Mer 140: 67-83.

Cantin, N. E., A. L. Cohen, K. B. Karnauskas, A. M. Tarrant, and D. C. McCorkle. 2010. Ocean warming slows coral growth in the central Red Sea. Science 329: 322-325. doi: 10.1126/science. 1190182

Caroselli, E., and others. 2011. Environmental implications of skeletal micro-density and porosity variation in two scleractinian corals. Zoology 114: 255-264. doi:10.1016/ j.zool.2011.04.003

Caroselli, E., G. Mattioli, O. Levy, G. Falini, Z. Dubinsky, and S. Goffredo. 2012a. Inferred calcification rate of a Mediterranean azooxanthellate coral is uncoupled with sea surface temperature along an $8^{\circ}$ latitudinal gradient. Front. Zool. 9: 32. doi:10.1186/1742-9994-9-32

Caroselli, E., F. Zaccanti, G. Mattioli, G. Falini, O. Levy, Z. Dubinsky, and S. Goffredo. 2012b. Growth and demography of the solitary scleractinian coral Leptopsammia pruvoti along a sea surface temperature gradient in the Mediterranean Sea. PLoS ONE 7: e37848. doi:10.1371/ journal.pone.0037848
Caroselli, E., V. Nanni, O. Levy, G. Falini, Z. Dubinsky, and S. Goffredo. 2015. Latitudinal variations in biometry and population density of a Mediterranean solitary coral suggest higher tolerance to seawater warming for nonzooxanthellate species. Limnol. Oceanogr. 60: 1356-1370. doi:10.1002/lno.10100

Caroselli, E., F. Ricci, V. Brambilla, G. Mattioli, O. Levy, G. Falini, Z. Dubinsky, and S. Goffredo. 2016a. Relationships between growth, population dynamics, and environmental parameters in the solitary non-zooxanthellate scleractinian coral Caryophyllia inornata along a latitudinal gradient in the Mediterranean Sea. Coral Reefs 35: 507519. doi:10.1007/s00338-015-1393-9

Caroselli, E., V. Brambilla, F. Ricci, G. Mattioli, O. Levy, G. Falini, Z. Dubinsky, and S. Goffredo. 2016b. Inferred calcification rate of a temperate non-zooxanthellate caryophylliid coral along a wide latitudinal gradient. Coral Reefs 35: 919-928. doi:10.1007/s00338-016-1422-3

Carricart-Ganivet, J. P. 2004. Sea surface temperature and the growth of the West Atlantic reef-building coral Montastraea annularis. J. Exp. Mar. Biol. Ecol. 302: 249-260. doi:10.1016/j.jembe.2003.10.015

Carricart-Ganivet, J. P., N. Cabanillas-Teràn, I. Cruz-Ortega, and P. Blanchon. 2012. Sensitivity of calcification to thermal stress varies among genera of massive reef-building corals. PLoS ONE 7: 32859. doi:10.1371/ journal.pone.0032859

Chadwick-Furman, N. E., S. Goffredo, and Y. Loya. 2000. Growth and population dynamics of the reefs coral Fungia granulosa Klunzinger, 1879 at Eilat, northern Red Sea. J. Exp. Mar. Biol. Ecol. 249: 199-218. doi:10.1016/S00220981(00)00204-5

Coma, R., M. Ribes, E. Serrano, E. Jimenez, J. Salat, and J. Pascual. 2009. Global warming-enhanced stratification and mass mortality events in the Mediterranean. Proc. Natl. Acad. Sci. USA 106: 6176-6181. doi:10.1073/ pnas.0805801106

Connell, J. H. 1973. Population ecology of reef building corals. In O. A. Jones and R. Endean [eds.], Biology and geology of coral reefs, v. II: Biology 1 . Academic Press.

Cooper, T. F., G. De 'Ath, K. E. Fabricius, and J. M. Lough. 2008. Declining coral calcification in massive Porites in two nearshore regions of the northern great barrier reef. Glob. Chang. Biol. 14: 529-538. doi:10.1111/j.13652486.2007.01520.x

Dodge, R., R. C. Aller, and J. Thomson. 1974. Coral growth related to the resuspension of bottom sediments. Nature 247: 574-577. doi:10.1038/247574a0

Epstein, N., R. P. M. Bak, and B. Rinkevich. 2001. Strategies for gardening denuded coral reef areas: The applicability of using different types of coral material for reef restoration. Restor. Ecol. 9: 432-442. doi:10.1046/j.1526100X.2001.94012.x 
Fantazzini, P., and others. 2015. Gains and losses of coral skeletal porosity changes with ocean acidification acclimation. Nat. Commun. 6: 7785. doi:10.1038/ncomms8785

Gerrodette, T. 1979. Ecological studies of two temperate solitary corals. Ph.D. thesis. Univ. of California San Diego.

Gizzi, F., V. Airi, E. Caroselli, and S. Goffredo. 2014. Modello di dinamica di popolazione del corallo solitario simbiotico Balanophyllia europaea (Scleractinia: Dendrophylliidae) a Calafuria. In Codice Armonico 2014. Quinto congresso di scienze naturali Ambiente toscano. Edizioni ETS.

Goffredo, S., and N. E. Chadwick-Furman. 2003. Comparative demography of mushroom corals (Scleractinia, Fungiidae) at Eilat, northern Red Sea. Mar. Biol. 142: 411418. doi:10.1007/s00227-002-0980-9

Goffredo, S., and F. Zaccanti. 2004. Laboratory observations of larval behavior and metamorphosis in the Mediterranean solitary coral Balanophyllia europaea (Scleractinia, Dendrophylliidae). Bull. Mar. Sci. 74: 449-458.

Goffredo, S., G. Mattioli, and F. Zaccanti. 2004. Growth and population dynamics model of the solitary coral Balanophyllia europea (Scleractinia, Dendrophylliidae). Coral Reefs 23: 433-443. doi:10.1007/s00338-004-0395-9

Goffredo, S., E. Caroselli, E. Pignotti, G. Mattioli, and F. Zaccanti. 2007. Variation in biometry and population density of solitary corals with solar radiation and sea surface temperature in the Mediterranean Sea. Mar. Biol. 152: 351-361. doi:10.1007/s00227-007-0695-Z

Goffredo, S., and H. R. Lasker. 2008. An adaptive management approach to an octocoral fishery based on BevertonHolt model. Coral Reefs 27: 751-761. doi:10.1007/s00338008-0391-6

Goffredo, S., E. Caroselli, G. Mattioli, E. Pignotti, and F. Zaccanti. 2008. Relationship between growth, population structure and sea surface temperature in the temperate solitary coral Balanophyllia europea (Scleractinia, Dendrophylliidae). Coral Reefs 27: 623-632. doi:10.1007/s00338008-0362-y

Goffredo, S., E. Caroselli, G. Mattioli, E. Pignotti, Z. Dubinsky, and F. Zaccanti. 2009. Inferred level of calcification decreases along an increasing temperature gradient in a Mediterranean endemic coral. Limnol. Oceanogr. 54: 930-937. doi:10.4319/1o.2009.54.3.0930

Goffredo, S., E. Caroselli, G. Mattioli, and F. Zaccanti. 2010. Growth and population dynamic model for the nonzooxanthellate temperate solitary coral Leptopsammia pruvoti (Scleractinia, Dendrophylliidae). Mar. Biol. 157: 2603-2612. doi:10.1007/s00227-010-1522-5

Goffredo, S., and others. 2012a. Unusual pattern of embryogenesis of Caryophyllia inornata (Scleractinia, Caryophylliidae) in the Mediterranean Sea. Maybe agamic reproduction? J. Morphol. 273: 943-956. doi:10.1002/ jmor.20039

Goffredo, S., and others. 2012b. The puzzling presence of calcite in skeletons of modern solitary corals from the
Mediterranean Sea. Geochim. Cosmochim. Acta. 85: 187199. doi:10.1016/j.gca.2012.02.014

Goffredo, S., and others. 2014. Biomineralization control related to population density under ocean acidification. Nat. Clim. Chang. 4: 593-597. doi:10.1038/nclimate2241

Grigg, R. W. 1977. Population dynamics of two gorgonian corals. Ecology 58: 278-290. doi:10.2307/1935603

Grigg, R. W. 1984. Resource management of precious corals: A review and application to shallow water reef building corals. Mar. Ecol. 5: 57-74. doi:10.1111/j.14390485.1984.tb00307.x

Grigg, R. W., and J. E. Maragos. 1974. Recolonizations of hermatypic corals on submerged lava flows in Hawaii. Ecology 55: 387-395. doi:10.2307/1935226

Guzner, B., A. Novoplansky, and N. E. Chadwick. 2007. Population dynamics of the reef-building coral Acropora hemprichii as an indicator of reef condition. Mar. Ecol. Prog. Ser. 333: 143-150. doi:10.3354/meps333143

Hamel, J. F., Z. Sun, and A. Mecier. 2010. Influence of size and seasonal factors on the growth of deep-sea coral Flabellum alabastrum in mesocosm. Coral Reefs 29: 521-525. doi:10.1007/s00338-010-0590-9

Harrison, P. L., and C. C. Wallace. 1990. Reproduction, dispersal and recruitment of scleractinian corals, p. 133-207. In Z. Dubinsky [eds.], Coral reefs. Elsevier.

Hernandez-Delgado, E. A., and others. 2014. Communitybased coral reef rehabilitation in a changing climate: Lessons learned from hurricanes, extreme rainfall, and changing land use impacts. Open J. Ecol. 14: 50930. doi: 10.4236/oje.2014.414077

Hudson, J. H. 1981. Growth rates in Montastraea annularis: A record of environmental change in Key Largo Coral Reef Marine Sanctuary, Florida. Bull. Mar. Sci. 31: 444-459.

Hughes, T. P. 1984. Population dynamics based on individual size rather than age: A general model with a reef coral example. Am. Nat. 123: 778-795. doi:10.1086/284239

Hughes, T. P., and J. B. C. Jackson. 1985. Population dynamics and life histories of foliaceous corals. Ecol. Monogr. 55: 141-166. doi:10.2307/1942555

Hughes, T. P., and J. H. Connell. 1987. Population dynamics based on size or age? A reef-coral analysis. Am. Nat. 129: 818-829. doi:10.1086/284677

Jackson, J. B. C. 1986. Modes of dispersal of colonial benthic invertebrates: Consequences for species' distributions and genetic structure of local populations. Bull. Mar. Sci. 39: 588-606.

Johnson, K. G. 1992. Population dynamics of a free-living coral: Recruitment, growth and survivorship of Manicina areolata (Linnaeus) on the Caribbean coast of Panama. J. Exp. Mar. Biol. Ecol. 225: 253-267. doi:10.1016/00220981(92)90173-8

Knittweis, L., J. Jompa, C. Richter, and M. Wolff. 2009. Population dynamics of the mushroom coral Heliofungia actiniformis in the Spermonde Archipelago, South Sulawesi, 
Indonesia. Coral Reefs 28: 793-804. doi:10.1007/s00338009-0513-9

Kruskal, W. H., and W. A. Wallis. 1952. Use of ranks in onecriterion variance analysis. J. Am. Stat. Assoc. 47: 583621. doi:10.2307/2280779

Kružić, P., P. Sršen, and L. Benković. 2012. The impact of seawater temperature on coral growth parameters of the colonial coral Cladocora caespitosa (Anthozoa, Scleractinia) in the eastern Adriatic Sea. Facies 58: 477-491. doi: 10.1007/s10347-012-0306-4

Lasker, H. R. 1990. Clonal propagation and population dynamics of a gorgonian coral. Ecology 71: 1578-1589. doi:10.2307/1938293

Lins de Barros, M. M., and D. O. Pires. 2006. Colony sizefrequency distributions among different populations of the scleractinian coral Siderastrea stellate in Southwestern Atlantic: Implications for life histories patterns. Braz. J. Oceanogr. 54: 213-223. doi:10.1590/S1679-87592006000300005

Lough, J. M. 2008. Coral calcification from skeletal records revisited. Mar. Ecol. Prog. Ser. 373: 257-264. doi:10.3354/ meps07398

Lough, J. M., and D. J. Barnes. 2000. Environmental controls on growth of the massive coral Porites. J. Exp. Mar. Biol. Ecol. 245: 225-243. doi:10.1016/S0022-0981(99)00168-9

Madin, J. S., T. P. Hughes, and S. R. Connolly. 2012. Calcification, storm damage and population resilience of tabular corals under climate change. PLoS ONE 7: e46637. doi: 10.1371/journal.pone.0046637

Marchini, C., and others. 2015. Annual reproductive cycle and unusual embryogenesis of a temperate coral in the Mediterranean Sea. PLoS ONE 10: e0141162. doi:10.1371/ journal.pone.0141162

Meesters, E. H., M. Hilterman, E. Kardinaal, M. Keetman, M. deVries, and R. P. M. Bak. 2001. Colony size-frequency distributions of scleractinian coral populations: Spatial and interspecific variation. Mar. Ecol. Prog. Ser. 209: 4354. doi:10.3354/meps209043

Muscatine, L., P. G. Falkowski, Z. Dubinsky, P. A. Cook, and L. R. McCloskey. 1989. The effect of external nutrient resources on the population dynamics of zooxanthellae in a reef coral. Proc. Biol. Sci. 236: 311-324. doi:10.1098/ rspb.1989.0025

Nozawa, Y., M. Tokeshi, and S. Nojima. 2008. Structure and dynamics of a high-latitude scleractinian coral community in Amakusa, southwestern Japan. Mar. Ecol. Prog. Ser. 38: 151-160. doi:10.3354/meps07342

Orejas, C., C. Ferrier-Pagès, S. Reynaud, A. Gori, E. Beraud, G. Tsounis, and J. M. Gili. 2011. Long-term growth rates of four Mediterranean cold-water coral species maintained in aquaria. Mar. Ecol. Prog. Ser. 429: 57-65. doi:10.3354/ meps09104

Pauly, D. 1984. Fish population dynamics in tropical waters: A manual for use with programmable calculators. International center for living and aquatic resources management.
Peirano, A., C. Morri, and C. N. Bianchi. 1999. Skeleton growth and density pattern of the temperate, zooxanthellate scleractinian Cladocora caespitosa from the Ligurian Sea (NW Mediterranean). Mar. Ecol. Prog. Ser. 185: 195201. doi:10.3354/meps185195

Peirano, A., M. Abbate, G. Cerrati, V. Difesca, C. Peroni, and R. Rodolfo-Metalpa. 2005. Monthly variations in calyx growth, polyp tissue, and density banding of the Mediterranean scleractinian Cladocora caespitosa (L.). Coral Reefs 24: 404-409. doi:10.1007/s00338-005-0020-6

Purser, A., A. I. Larsson, L. Thomsen, and D. Van Oevelen. 2010. The influence of flow velocity and food concentration on Lophelia pertusa (Scleractinia) zooplankton capture rates. J. Exp. Mar. Biol. Ecol. 395: 55-62. doi:10.1016/ j.jembe.2010.08.013

Rodolfo-Metalpa, R., A. Peirano, F. Houlbrèque, M. Abbate, and C. Ferrier-Pagès. 2008. Effect of temperature, light and heterotrophy on the growth rate and budding of the temperate coral Cladocora caespitosa. Coral Reefs 21: 1725. doi:10.1007/s00338-007-0283-1

Sakai, K. 1998. Effect of colony size, polyp size, and budding mode of egg production in a colonial coral. Biol. Bull. 195: 319-325. doi:10.2307/1543143

Santangelo, G., E. Maggi, L. Bramanti, and L. Bongiorni. 2004. Demography of the over-exploited Mediterranean red coral (Corallium rubrum L. 1758). Sci. Mar. 68: 199204. doi:10.3989/scimar.2004.68s1199

Sebens, K. P. 1987. The ecology of indeterminate growth in animals. Annu. Rev. Ecol. Syst. 18: 371-407. doi:10.1146/ annurev.ecolsys.18.1.371

Sparre, P., E. Ursin, and S. C. Venema. 1989. Introduction to tropical fish stock assessment. FAO Fisheries Technical Paper no. 306. FAO.

Sparre, P., and S. C. Venema. 1998. Introduction to tropical fish stock assessment. Part 1: Manual. FAO Fisheries Technical Paper No. 306, Rev. 2. FAO.

Tanzil, J. T. I., B. E. Brown, A. W. Tudhope, and R. P. Dunne. 2009. Decline in skeletal growth of the coral Porites lutea from Andaman Sea, South Thailand between 1984 and 2005. Coral Reefs 28: 519-528. doi:10.1007/ s00338-008-0457-5

Teixido, N., J. Garrabou, and J. G. Harmelin. 2011. Low dynamics, high longevity and persistence of sessile structural species dwelling on Mediterranean coralligenous outcrops. PLOS ONE 6: e23744. doi:10.1371/journal.pone. 0023744

Vardi, T., D. E. Williams, and S. A. Sandin. 2012. Population dynamics of threatened elkhorn coral in the northern Florida Keys, USA. Endang. Species Res. 19: 157-169. doi: 10.3354/esr00475

Vertino, A., A. Savini, A. Rosso, I. Di Geronimo, F. Mastrototaro, R. Sanfilippo, and G. Etiope. 2010. Benthic habitat characterization and distribution from two representative sites of the deep-water SML Coral Province 
(Mediterranean). Deep-Sea Res. Part II 57: 380-396. doi: 10.1016/j.dsr2.2009.08.023

Von Bertalanffy, L. 1938. A quantitative theory of organic growth (inquires on growth laws II). Hum. Biol. 10: 181-213.

Vongsavat, V., P. Winotai, and S. Meejoo. 2006. Phase transitions of natural corals monitored by ESR spectroscopy. Nucl. Instrum. Methods B. 243: 167-173. doi:10.1016/ j.nimb.2005.07.197

Yamashiro, H., and M. Nishira. 1998. Experimental study of growth and asexual reproduction in Diaseris distorta (Michelin, 1843), a free-living fungiid corals. J. Exp. Mar. Biol. Ecol. 225: 253-267. doi:10.1016/S0022-0981(97)00229-3

Zibrowius, H. 1980. Les scléractiniaires de la Méditeranée et de l'Atlantique nord-oriental. Mem. Inst. Oceanogr. (Monaco) 11: 1-284.

\section{Acknowledgments}

The research leading to these results has received funding from the European Research Council under the European Union's Seventh Framework Programme (FP7/2007-2013)/ERC grant agreement $n^{\circ}$ [249930CoralWarm: Corals and global warming: the Mediterranean versus the Red Sea]. The Scientific Diving School (www.sdseducational.org) gave logistical support for fieldwork. The experiment complied with current Italian law.

\section{Conflict of Interest}

None declared.

Submitted 05 April 2016 Revised 19 July 2016; 12 October 2016 Accepted 01 November 2016

Editor: Robert Howarth 